\title{
Optimization of Drilling Parameters of E- Glass Composite using Taguchi Method
}

\author{
Varad S. Upadhye ${ }^{1}$ \\ ${ }^{1}$ UG. Student, \\ Department of Mechanical Engineering, \\ RMD Sinhgad School of Engineering, \\ Maharashtra, India
}

\author{
Atharva S. Hasabnis ${ }^{2}$ \\ ${ }^{2} \mathrm{UG}$. Student, \\ Department of Mechanical Engineering , \\ RMD Sinhgad School of Engineering, \\ Maharashtra, India
}

\begin{abstract}
Currently composites area unit being employed to interchange standard metallic materials during a wide range of industries together with aerospace, craft and defense that need structural materials with high strength-to-weight and stiffness-toweight ratios. GFRP composites area unit employed in fairings, rider compartments, and storage room doors due to their high mechanical properties. Out of all the machining operations, most ordinarily used operation is drilling. however drilling of those composite materials, no matter the appliance space, are often thought of a essential operation, owing to their tendency to delaminate once subjected to mechanical stresses. With relevance the standard of machined element, the principal drawbacks are associated with surface delamination, fibre/resin pull-out and inadequate surface roughness of the opening wall. therefore it's essential to know the drilling behaviour by conducting an outsized variety of drilling experiments and drilling parameters like feed rate and spindle speed ought to be optimized. The improvement of method parameters done by Taguchi's $\mathrm{S} / \mathrm{N}$ ratio analysis for delamination in drilling of GFRP composites. GFRP composite is fabricated using epoxy polymer Araldite LY556 matrix reinforced with twelve layers of glass fibers. The $\mathrm{S} / \mathrm{N}$ ratio values are calculated by taking into thought with the help of package Minitab 17. The Surface Roughness worths measured and their optimum value for minimum Surface Roughness is known.
\end{abstract}

Key Words: Drilling parameter, GFRP composites, surface roughness

\section{INTRODUCTION}

Mankind was attentive to and using composite materials from history in up the standard of life. In recent times the development and application of composite materials altogether branches of engineering square measure occurring at an progressively quick pace. modern composites square measure the results of analysis and innovations throughout the previous couple of decades once these progressed from glass fiber for vehicles to particulate composites for region. Some outline composite as "materials composed of 2 or a lot of clearly acknowledgeable constituents". however modern composites developed for specific functions like flake, particulate and laminal composites defy such definitions. Fibers or particles embedded in matrix of another material that square measure largely structural are latest developments. GFRP composites square measure utilized in fairings, traveler compartments, storage room doors due to their high mechanical properties. Drilling improvisation bit is that the commonest operation of secondary machining for fiber-reinforced materials. However, composite laminates are regarded as hard-to-machine materials, which ends in low drilling potency and undesirable drillinginduced delamination. For rivets and fastened joints, damage- free and precise holes should be trained within the parts to make sure high joint strength and exactness. However, composite laminates square measure non-homogeneous, aeolotropic, and extremely abrasive and have laborious reinforcement fibers, that build them troublesome to machine. Light weight and fewer thermal physical phenomenon. Hole creating operation is crucial for any style of material for connection of mechanical fasteners using rivets, screws and bolts. Drilling of glass fiber reinforced polymers (GFRP) composites is troublesome as compared with drilling on metals this can be due to GFRP's inherent property and in homogeneity. Machining on composites results fibre pullouts, fibre breakout, fracture, small cracking, breakage of organic compound and delamination round the trained hole, these ends up in cut back the composites strength. glass fiber strengthened reinforced (GFRP) are utilized in wide areas of engineering applications in many industries like energy sector, automotive, aircrafts, marine, natural philosophy, etc. as a result of low price and superior mechanical properties like high specific strength, lightweight weight, corrosion resistant and low thermal physical phenomenon. Machining of GFRP is difficult due to non-homogeneity and aeolotropic nature. usually GFRP composites square measure ready in laminated kind by incorporating sturdy and brittle fibers as reinforcement in soft and ductile compound as matrix. Experiments are allotted to ascertain correlation between cutting speed and feed rate with the precise cutting pressure, thrust force, injury issue and surface roughness in GFRP material invented by Hand lay-up technique. Drilling is that the most often used machining method in industries to assemble mechanical parts. Drilling of GFRP leads to drawbacks like delamination at the doorway and exit, fibre fallback and poor surface end. Considering the productivity and value of drilling, improvement of method parameters is very important to urge higher Material Removal Rate.

\subsection{PROBLEM DEFINATION}

Optimizing the machining parameters such as spindle speed, feed rate and Drill Diameter by using Taguchi. Different turning experiments are carried out on Double Column All Geared Auto Feed Radial Drill Machine by varying two parameters and keeping the other parameter constant and optimizing the surface roughness.

\subsection{OBJECTIVE}

- To manufacturing of glass fiber reinforced plastics specimen with varying concentration of epoxy resin using 


\section{Hand lay-up method.}

- To perform experimental drilling process on three different specimen

- To optimize the machining parameters such as spindle speed, feed rate and Drill Diameter.

- To calculate the optimum value of Surface Roughness for GFRP composites specimen

\subsection{PURPOSE}

Purpose of this paper is to inspect different parameters which influence the machining process of GFRP composites, for example cutting speed, feed and drill bit type and their significance in choosing the surface roughness

\subsection{SCOPE}

This project considers on investigating of Optimization of Surface Roughness. It will start with literature review and understands the statement of problem. In addition, the effect of major parameters influencing the surface roughness due to machining also will be discussed.

\section{LITERATURE REVIEW}

P. Koushik Kumar et. al. [1] The rising patterns of material innovation strived the improvement of composite materials. This improved properties of composite materials advanced their applications in car and avionic business. Overlaid composites discovered wide spread applications as opposed to others because of their simplicity of assembling. Machining of covered composites is fundamental to have utilitarian consequences; out of which penetrating is the key activity required for manufacture. In this paper a basic survey on mechanical penetrating of composite overlays is introduced. It is meant to cover penetrating activities, boring apparatus geometry and materials, delamination in boring and its cures, push power and instrument wear.. Boring procedure on composite overlays is fundamental for attaching with different materials to have helpful results.

Y. Karpat et. al. [2] Carbon fiber strengthened plastics (CFRPs) have attractive material properties that fulfill the aeronautic trade's high solidarity to weight proportion objective. In this manner, CFRPs are regularly utilized in auxiliary parts, either alone or along with aluminum and titanium amalgams. Boring of CFRPs has been concentrated widely in the writing as of late, with exceptional accentuation on process boundaries and delamination. This investigation recognizes mechanical properties of uni-directional CFRPs through penetrating tests. Boring of uni-directional CFRP plates with and without pilot gaps has been performed, and cutting and edge power coefficients are recognized. A polycrystalline precious stone (PCD) drill was utilized in tests since this sort of drill is usually utilized by and by. At last, approval tests on multi directional CFRP overlays have been performed and acceptable outcomes have been acquired. CFRPs are known to be hard to machine because of the grating nature and low warm conductivity. CFRP penetrating has been the subject of numerous examinations in the writing, the vast majority of which think about the impact of boring conditions on delamination.
Alessandra Caggiano et. al. [3] Fiber strengthened plastic composite materials are hard to machine as a result of the anisotropy and in homogeneity describing their microstructure and the abrasiveness of their fortification segments. During machining, quick cutting apparatus wear improvement is experienced, and surface uprightness harm is frequently created in the machined parts. A precise determination of the best possible instrument and machining conditions is in this way required, considering that the marvels answerable for material expulsion in cutting of fiber strengthened plastic composite materials are in a general sense not quite the same as those of regular metals and their amalgams. Until this point in time, composite materials are progressively utilized in a few assembling areas, for example, the aviation and car industry, and a few research endeavors have been spent to improve their machining forms.

V. Krishnaraj et. al. [4] In this paper, test and numerical investigation of penetrating of carbon fiber fortified plastic (CFRP) cover with aluminum compound stacks has been done. Boring of these multi-materials is a provoking undertaking to assembling engineers due to various mechanical properties of materials. In this work, the effect of the machining boundaries on the impact of curve drill and the geometry of twofold cone drill on cutting powers, openings quality and on CFRP/Al interface have been explored. From the test study, it was discovered that the twofold cone drills initiate less push power contrasted with the standard wind drill.

\section{TAGUCHI METHOD}

Genichi Taguchi is that the name of a Japanese engineer who has been active within the improvement of Japan's industrial merchandise and processes since the late Nineteen Forties, once the Second war. Taguchi's major contribution has concerned combining engineering and applied math ways to realize fast enhancements in price and quality by optimizing product design and producing processes. Taguchi methods represent a brand new philosophy during which quality is measured by the deviation of a purposeful characteristic from its target price. A Taguchi design may be a designed experiment that permits you to opt for a product or method that functions additional systematically within the operative surroundings. Taguchi styles recognize that not all factors that cause variability may be controlled. These uncontrollable factors area unit known as noise factors. Taguchi styles try and determine manageable factors (control factors) that minimize the result of the noise factors i.e. planning a product or method in such how thus on create its performance less sensitive to variation thanks to uncontrolled or noise variables that aren't economical to manage.

\subsection{FABRICATION OF GFRP COMPOSITE}

In this experiment, GFRP composites were fabricated by Hand layup technique. For the fabrication of GFRP composite, Epoxy polymer (Araldite LY 556) and Hardener (HY 951) were taken in the ratio of $10: 1$ by weight by using micro weighing balance. E-glass bi-oven fibers were cut according to the size of mold. The gel was sprayed inside the mold as a releasing agent. Alternate layers of epoxy i.e. epoxy resin with hardener and Eglass fiber laminate was placed until the desired thickness $(1 \mathrm{~cm}$ 
- 12 layers) was achieved. The orientation of fiber laminate was kept same throughout all the layers. The whole composite was allowed to cure at room temperature for $36 \mathrm{hrs}$. The care has been taken to maintain the uniform cross section of composite as much as possible. Because any variation in cross section can lead to stress concentration which will may lead to breaking of composite sample from that point only.

\subsection{Drilling}

The experiment was conducted on a Radial \& pillar drilling machine by using HSS drill bits in dry conditions. Experiments were conducted by choosing different levels of input parameters for cutting speeds, feed rates, and diameter of drill bits. 42 mm cap. Double Column All Geared Auto Feed Radial Drill Machine

\begin{tabular}{|c|c|}
\hline DESCRIPTION & DC-410 \\
\hline Drilling in M.S. & $42(15 / 8 ”)$ \\
\hline Drilling in C.I. & 50 \\
\hline Rough Boring in M.S. & 60 \\
\hline Tapping in M.S. & 25 \\
\hline Spindle Taper & MT-4 \\
\hline Spindle Travel & 225 \\
\hline $\begin{array}{l}\text { Spindle Speeds } \text { (RPM } x \\
\text { steps) }\end{array}$ & $\begin{array}{l}12 \text { Steps } \\
60,90,115,165,200 \text {, } \\
290,340,480,575, \\
625,1005,1510\end{array}$ \\
\hline Diameter of RAM (quill) & 78 \\
\hline Spindle Autofeed Ranges & $\begin{array}{l}6 \text { Steps } \\
0.1,0.15,0.20,0.27 \\
0.33,0.52\end{array}$ \\
\hline $\begin{array}{l}\text { Max/Min Dist. Spindle nose } \\
\text { to base }\end{array}$ & $1225 / 450$ \\
\hline Vertical Travel of Arm & 775 \\
\hline $\begin{array}{l}\text { Max/Min Dint. Spindle } \\
\text { center to column }\end{array}$ & $1025 / 275$ \\
\hline Horizontal Travel of Arm & 750 \\
\hline Max. Drilling Radius & 1137 \\
\hline $\begin{array}{l}\text { Machine Measurement (LX } \\
\text { B X H) }\end{array}$ & $1600 \times 850 \times 2270$ \\
\hline Diameter of Column & 225 \\
\hline Work Table & $550 \times 450 \times 400$ \\
\hline Coolant Tank & $\begin{array}{l}770 \times 430 \times 145 \\
50 \text { liters }\end{array}$ \\
\hline Drill-head Motor & $\begin{array}{l}2 \mathrm{HP}(1.5 \mathrm{KW}) \\
960 / 1440 \mathrm{RPM}\end{array}$ \\
\hline
\end{tabular}

The number of factors and levels are considered based on literature and parameters range as shown in Table I.

Table -1: Drilling Parameters And Different Levels

\begin{tabular}{|l|l|l|l|}
\hline $\begin{array}{l}\text { Drilling parameters/ } \\
\text { Factors }\end{array}$ & Level 1 & Level 2 & Level 3 \\
\hline Speed (rpm) & 200 & 825 & 1510 \\
\hline Feed rate (mm/rev) & 0.16 & 0.31 & 0.5 \\
\hline Drill Diameter $(\mathrm{mm})$ & 4 & 8 & 12 \\
\hline
\end{tabular}

\section{EXPERIMENTAL TESTING}

The following Procedure were carried

- The specimens are drilled on Double Column All Geared Auto Feed Radial Drill Machine.

- $\quad$ The Speed, Feed \& Depth of Drill Diameter for Turning operation were first decided.

- We decided 3 speed, feed \& Drill Diameter value
- $\quad$ After that the Orthogonal Array was formed with the help of MINITAB Software.

- According to that Orthogonal Array, nine Turning Operations were carried out on Double Column All Geared Auto Feed Radial Drill Machine

- The Surface Hardness testing was carried out for all the specimens.

- Then all the values of Surface roughness were put down in MINITAB software \& Analyzed as the TAGUCHI design.

- After getting the graph, the optimum Solution was drawn.

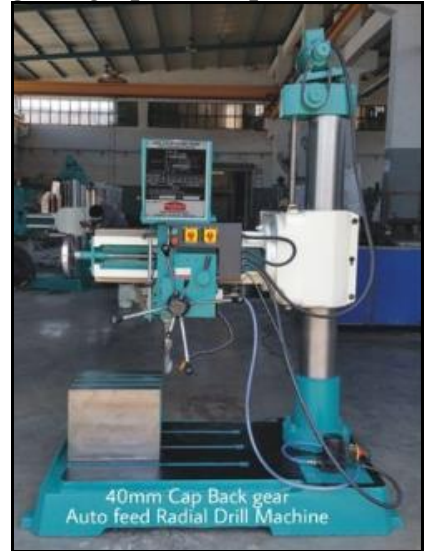

Fig 1 Double Column All Geared Auto Feed Radial Drill Machine

\section{STEPS CARRIED OUT IN MINITAB}

Before using Minitab, we need to choose Independent factors such as speed, feed \& Drill Diameter for the inner array and Dependent factors such as Surface Roughness for the outer array. Independent factors are factors we can control to optimize the process. Dependent factors are factors that can affect the performance of a system but are not in control during the intended use of the product.

Minitab can help us design a Taguchi experiment that does not confound interactions of interest with each other or with main effects.

Conducting a Taguchi designed experiment can have the following steps:

Choose Stat $>$ DOE $>$ Taguchi $>$ Create Taguchi Design to generate a Taguchi design (orthogonal array). Each column in the orthogonal array represents a specific factor with two or more levels. Each row represents a run; the cell values identify the factor settings for the run. By default, Minitab's orthogonal array designs use the integers $1,2,3$, to represent factor levels. If we enter factor levels, the integers $1,2,3$, will be the coded levels for the design. We can also use Stat > DOE > Taguchi > Define Custom Taguchi Design to create a design from data that we already have in the worksheet. Define Custom Taguchi Design lets specify which columns are our factors and signal factors. We can then easily analyses the design and generate plots.

After we create the design, we can display or modify the design: Choose Stat $>$ DOE $>$ Display Design to change the units (coded or uncoded) in which Minitab expresses the factors in the worksheet.

Choose Stat $>$ DOE $>$ Modify Design to rename the factors, change the factor levels, add a signal factor to a static design, 
ignore an existing signal factor (treat the design as static), and add new levels to an existing signal factor.

Conduct the experiment and collect the response data. The experiment is done by running the complete set of factor settings at each combination of control factor settings (at each run). The response data from each run of the noise factors in the outer array are usually aligned in a row, beside the factor settings for that run of the control factors in the inner array.

\begin{tabular}{|l|l|l|l|}
\hline $\begin{array}{l}\text { Experiment } \\
\text { No. }\end{array}$ & $\begin{array}{l}\text { Speed } \\
(\mathrm{rpm})\end{array}$ & $\begin{array}{l}\text { Feed rate } \\
(\mathrm{mm} / \mathrm{rev})\end{array}$ & $\begin{array}{l}\text { Drill dia. } \\
(\mathrm{mm})\end{array}$ \\
\hline 1 & 200 & 0.16 & 4 \\
\hline 2 & 200 & 0.31 & 8 \\
\hline 3 & 200 & 0.5 & 12 \\
\hline 4 & 825 & 0.16 & 8 \\
\hline 5 & 825 & 0.31 & 12 \\
\hline 6 & 825 & 0.5 & 4 \\
\hline 7 & 1510 & 0.16 & 12 \\
\hline 8 & 1510 & 0.31 & 4 \\
\hline 9 & 1510 & 0.5 & 8 \\
\hline
\end{tabular}

Table -2 : Orthogonal Array of GFRP composites specimen Choose Stat $>$ DOE $>$ Taguchi $>$ Analyse Taguchi Design to analyse the experimental data.

\section{Note}

We should analyze each response variable separately with Taguchi designs. Although Taguchi analysis accepts multiple response columns, these responses should be the same variable measured under different factor conditions.

Choose Stat $>$ DOE $>$ Taguchi $>$ Predict Taguchi Results to predict signal to noise ratios and response characteristics for selected new factor settings.

\section{PROCEDURE FOR CALCULATION OF MATERIAL COST}

The general procedure for calculation of material cost estimation is after designing a project,

1. A bill of material is prepared which is divided into two categories.
a. Fabricated components
b. Standard purchased components

2. The rates of all standard items are taken and added up.

3. Cost of raw material purchased taken and added up.

\begin{tabular}{|c|c|c|}
\hline SR.NO. & COMPONENTS & COST \\
\hline 1. & Glass fibre & 3000 \\
\hline 2. & Epoxy Resin & 2000 \\
\hline 3. & Testing & 5000 \\
\hline
\end{tabular}

Total Cost of Project $=$ Cost of Components + other cost $=$ $10000 /-$

\section{CONCLUSIONS}

The present study investigates the optimization of drilling parameters of GFRP composites Specimen using Taguchi Method. The optimization is carried out by using MINITAB 17 software. optimize the parameters namely cutting speed, feed rate and drill diameter to maximize the MRR and minimize the delamination damage in drilling of GFRP. The results of the study are as follows: The optimum values of parameters for maximum MRR are cutting speed of $1510 \mathrm{rpm}$, feed rate of 0.5 $\mathrm{mm} / \mathrm{rev}$ and drill diameter of $12 \mathrm{~mm}$.

\section{REFERENCES}

[1] B. Ravi Sankar, P. Umamaheswarrao, A.V. Avinash Reddy , P. Koushik Kumar," Drilling of Composite Laminates- A Review". Journal of Basic and Applied Engineering Research Print ISSN: 2350-0077; Online ISSN: 2350-0255; Volume 1, Number 3; October, 2014 pp. 19-24

[2] Y. Karpat , O. Bahtiyar , B. Deg־er , Bilgin Kaftanog־lu," A mechanistic approach to investigate drilling of UD-CFRP laminates with PCD drills." CIRP Annals - Manufacturing Technology 63 (2014) 81-84

[3] Alessandra Caggian," Machining of Fibre Reinforced Plastic Composite Materials", Materials 2018, 11, 442; doi:10.3390/ma11030442.

[4] Redouane Zitoune, V. Krishnaraj, Francis Collombet, Sabine Le Roux, " Experimental and numerical analysis on drilling of carbon fibre reinforced plastic and aluminium stacks." Elsevier, 2016, 146, pp.148158. ff10.1016/j.compstruct.2016.02.084ff. ffhal-01620291f

[5] B.P. Mishra, D. Mishra, P. Panda."Drilling of glass fibre reinforced polymer /nanopolymer composite laminates." International Journal of Advanced Mechanical Engineering. ISSN 2250-3234 Volume 8, Number 1 (2018), pp. 153-172 